made through D.C. silicone fluid 200. 'The energyresolution was tested by passing mono-energetic electrons into the crystal along its axis. Fig. 1 shows the photomultiplier pulse-height spectrum for an incident energy of $140 \mathrm{MeV}$. The resolution is about 40 per cent. The mean pulse-height corresponds to approximately 44 photoelectrons from the multiplier cathode, that is, about $0 \cdot 3$ electron per $\mathrm{MeV}$. The poor resolution is thought to be due to the variation in the fraction of the incident energy trapped in the crystal; this variation can only be reduced by increasing the size of the crystal. The mean pulseheight almost corresponds to that predicted.

This behaviour can be compared with that of a similar instrument built by Cassels. His absorber was a glass cylinder, $20 \mathrm{~cm}$. long and $12 \cdot 5 \mathrm{~cm}$. diameter (8 and 5 radiation-lengths respectively). This instrument measured the energy of $125-\mathrm{MeV}$. electrons with about 30 per cent resolution and gave pulses corresponding to 0.7 photoelectron per $\mathrm{MeV}$. This suporiority is expected, as a glass absorber of comparable dimensions to a lead fluoride absorber will give a greater Cerenkov light output due to the longer total electron-path at the same energy. However, light collection is more difficult.

These results indicate that in the range $50-300$ $\mathrm{MeV}$. lead glass is the better absorber, since the size required is still manageable. A lead tluoride absorber has, however, only one-third the linear dimensions of the equivalent glass absorber ; therefore, at energies where the lead glass required is too large, lead fluoride will be more convenient. The resolution should improve as the energy increases.

We are indebted to Prof. R. V. Jones and Dr. D. A. Jones, of the University of Aberdeen, for the gift of the lead fluoride crystal, and to Prof. P. I. Dee for encouragement and useful discussion.

W. S. C. WILLIAMS

H. S. Caplan

Department of Natural Philosophy,

The University,

Glasgow, W.2. April 8.

I Kantz, A., and Hofstadter, R., Nucleonics, 12, 36 (1954).

'Cassels, J. M., Proc. Phys. Soc. (in the press). Wo are indebted to Prof. Cassels for supplying this information about his instrument prior to publication.

- Jester, M. H. L., University of California Radiation Laboratory, 2990 (1955).

- Jones, D. A., Proc. Phys. Soc., B, 65, 165 (1955).

\section{Ionization Potentials of Hydrogen Fluoride and the Ground-State of the HF+ Ion}

Johns and Barrow ${ }^{1}$ have recently reported the results of their ultra-violet spectroscopic studies of the $\mathrm{DF}^{+}$and $\mathrm{HF}^{+}$molecular ions. They concluded that the observed bands were due to transitions between a lower $A$-state and an upper $B$-state. The $A$-state was regarded as being the $A^{2} \Sigma+$-state arising from the combination $\mathrm{H}++\mathrm{F}\left({ }^{2} P\right)$. Johns and Barrow state that if $A^{2} \Sigma+$ is the ground-state of the $\mathrm{HF}+$ ion, then the ionization potential of HF would be $16.88 \mathrm{eV}$.

The ground-states of the $\mathrm{HCl}+$ and $\mathrm{HBr}^{+}$molecular ions are ${ }^{2} \Pi_{\boldsymbol{i}}$-states arising from the combination $\mathrm{H}+\mathrm{X}+\left({ }^{8} P\right)$. This ${ }^{2} \Pi_{i}$-state could, of course, be the ground-state of $\mathrm{HF}+$

Recently, we determined the ionization potentials of $\mathrm{HF}$, using essentially mono-energetic electrons ${ }^{2}$, and found that the first ionization potential was $15 \cdot 77 \mathrm{eV}$. and that there is another ionization potential at about $1 \cdot 2 \mathrm{eV}$. above this due to the formation of the $\mathrm{HF}+$ ion in its first excited state. A detailed consideration of the electronic structure of the HF molecule led us to conclude that the ionization potential at $15 \cdot 77 \mathrm{eV}$. refers to the formation of the $\mathrm{HF}+$ ion in its ${ }^{2} \mathrm{II}_{i}$-state, and the second ionization potential refers to the formation of $\mathrm{HF}+$ ion in its first excited $A^{2} \Sigma+$-state. Bands due to the transitions $A^{2} \Sigma+-{ }^{2} \Pi_{i}$ and $B^{2} \Sigma+-{ }^{2} \Pi_{i}$ are therefore still to be found for the HF+ ion. Our results indicate that the former bands should be found in the near infra-red.

A detailed discussion of these matters is conteined in a paper presented at the annual conference of the Chemical Institute of Canada held in Vancouver, B.C., June 3-5, 1957.

\section{J. A. R. Coope \\ D. C. Frost \\ C. A. McDowell}

Department of Chemistry,

University of British Columbia, Vancouver 8, B.C.

'Johns, J. W. C., and Barrow, R. F., Nature, 179, 374 (1957).

Fox, R. E., Hickam, W. M., Kjeldaas, jun., T., and Grove, D. J., Phys. Rev., 84, 859 (1951). Frost, D. C., and McDowell, C. A.,

IT is very satisfactory that evidence for the ${ }^{2} \Pi_{i}$-state of $\mathrm{HF}+$, which proves to be the groundstate, has now been obtained, and the agreement between the electron impact value of the ionization potential to $A^{2} \Sigma+, 15 \cdot 77+1 \cdot 2=16 \cdot 9, \mathrm{eV}$., and the spectroscopic and thermochemical value, $16 \cdot 88 \mathrm{eV}$., is very good. Comparison with $\mathrm{HCl}$ and $\mathrm{HBr}$ suggests that $\omega_{e}^{\prime \prime}$ and $r_{e}{ }^{\prime \prime}$ for $\mathrm{HF}+$ should have values similar to those for the ground-state of the neutral molecule. The relative dispositions of the potential curves (Fig. 1 ) aro such that the transition $B-X$

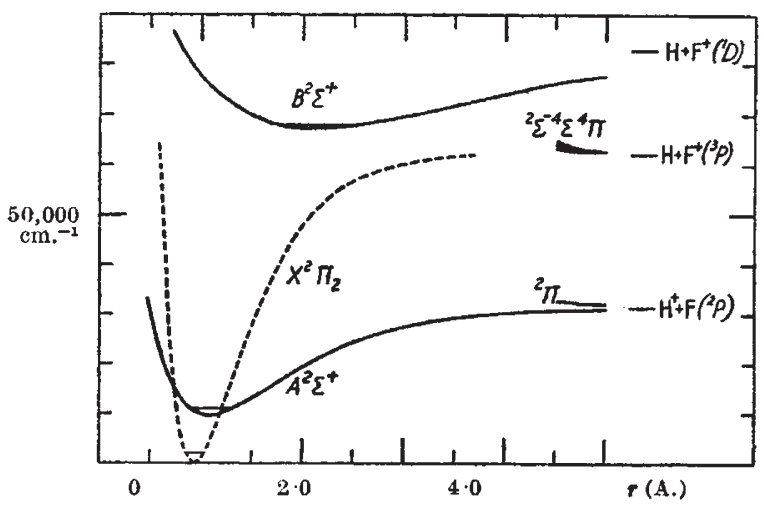

Fig. 1. Morse potential energy-internuclear distance curves for electronic states of $\mathrm{HF}^{+}$

in the ultra-violet region must be weak: however, it seems likely that the $A-X$ transition should be observable. The 0,0 band should lie at about $11,200 \mathrm{~A}$., and the 1,0 band at about $8500 \mathrm{~A}$.

J. W. C. JoHns

R. F. BARROW

Physical Chemistry Laboratory, University of Oxford. 